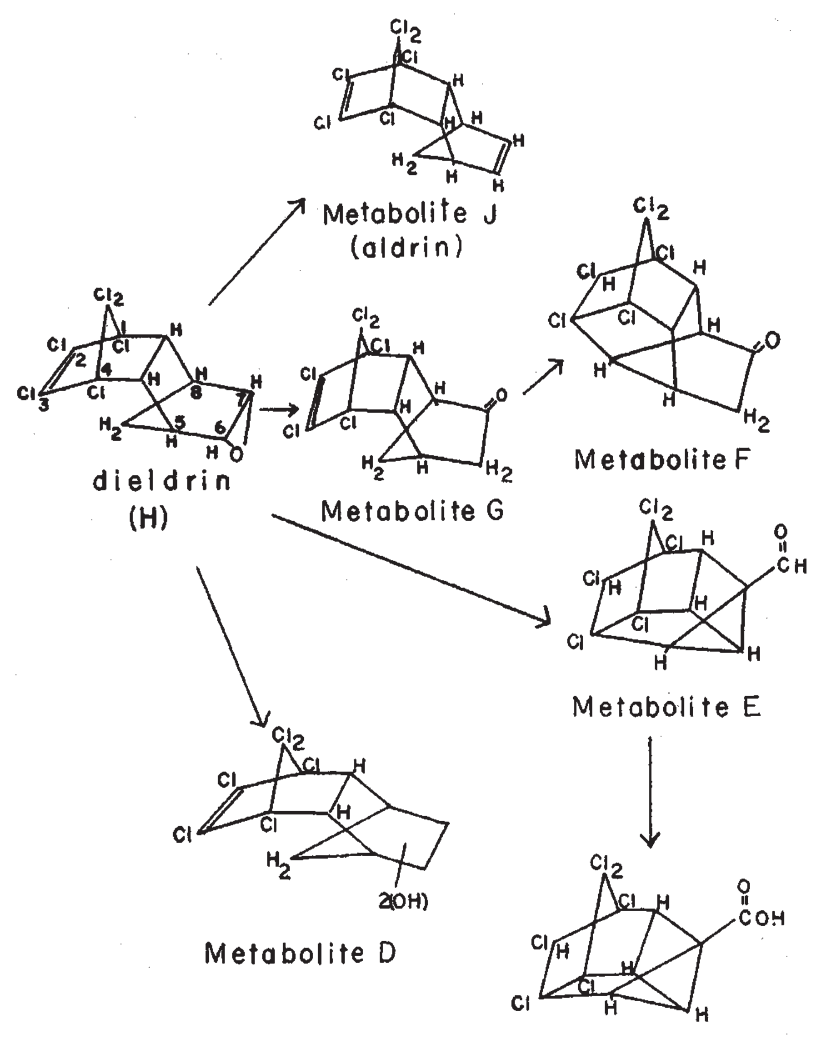

Acidic component?

Fig. 2. Proposed dieldrin degradation pathways by the micro-organism in soll. The structures of metabolites $G$ and $F$ were established, $F$ being one of the stable "terminal residues". The structures shown for $E$ and the resulting acidic metabolite are the most likely ones. The structura arrangement of those two hydroxyl groups in metabolite $D$ is

on the loss of one of the hydroxyl groups through dehydration. It cannot therefore be trans-6,7-dihydrodihydroxyaldrin, which directly forms the peak group at 361 on fragmentation. Another prominent peak group was at 325 , possibly resulting from $\mathrm{M}-2\left(\mathrm{H}_{2} \mathrm{O}\right)$ fragmentation.

With the exception of aldrin, all the metabolites previously mentioned do not exist in nature, and it is there. fore important to study their toxicological effects on various ecosystems in our environment. The quantity of the metabolites finally purified in this study was, however, not enough to permit fully fledged toxicological investigations. Metabolite $F^{\top}$ seemed to be one of the stable "terminal residues", and thus its toxicological meaning in relation to the problems of environmental contamination should be carefully assessed in the future.

This work was supported by a research grant from the US Public Health Service, from the National Communicable Disense Center, Atlanta, Georgia.

F. Matsumura G. M. Boush Akira Tar

Department of Entomology,

University of $W$ isconsin,

Madison.

Received June 17; revised July 8, 1968.

${ }^{1}$ Matsumura, F., and Boush, G. M., Science, 156, 959 (1967). 2 Fred, E. B., and Waksman, S. C., Laboratory Manual of General Microbiology
(MeGraw-Hill, New York, 1958).

${ }^{3}$ Matsumura, F., and Boush, G. M., J. Econ. Entomol., 61, 610 (1968).

- Robinson, J., Richardson, A., and Bush, B., Bull. Env. Contam. Toxicol., 1, $127(1966)$. Rosen, J. D., Sutherland, D. J., and Lipton, G. R., Bull. Env. Contam. Toxicol., 1, 133 (1966).

${ }^{5}$ Phillips, D. D., Pollard, G. E., and Soloway, S. B., Agric. Food Chem, 10,
217 (1962).

\section{Isolation and Biological Activity of a Microbial Conversion Product of Aflatoxin $B_{1}$}

ONE of the most striking and significant developments in synthetic chemistry has been the use of biological systems to achieve chemical transformations, especially the oxidation-reduction of steroids and alkaloids. Based on an analogous biological system, we have attempted to transform aflatoxin $\mathrm{B}_{1}$, a toxic secondary metabolite of Aspergillus flavus, by employing a known steroid. hydroxylating micro-organism.

Our original objective was to produce the hydroxylated aflatoxin (aflatoxin $\mathbf{M})^{1}$ by incubating it in the presence of a known steroid-hydroxylating fungus (Dactylium dendroides $)^{2}$. In preliminary work on the hydroxylation of aflatoxin $\mathrm{B}_{1}$, a new, blue-fluorescent compound was produced as demonstrated by thin-layer chromatography (TLC). We have tentatively designated this new derivative (Ro).

Dactylium dendroides NRRL 2575 was grown on a yeast extract-sucrose medium in $10-30 \mathrm{mg}$ of crystalline aflatoxin $B_{1}$ per flask. After incubation for $48 \mathrm{~h}$ the culture flasks were extracted with chloroform; this crude extract contained aflatoxin and several other fluorescent compounds. Chromatography of the crude extract on a silicic acid column with 1 per cent ethanol in chloroform gave a brown fraction containing aflatoxins $B_{1}$ and Ro. These two compounds were separated on a column of 'Silica Gel G-HR' with 10 per cent acetone in chloroform. The eluate (Ro) was concentrated, the compound precipitated by hexane addition and the precipitate taken to dryness.

Compound (Ro) was originally thought to be aflatoxin $\mathrm{B}_{2}$ because of an equivalent $R_{F}$ value on 'Silica Gel $G-H R$ ' thin-layer chromatography plates when 10 per cent acetone in chloroform was used as developing solvent. Development of the plates with either 20 per cent acetone in chloroform or 2 per cent $\mathrm{CH}_{3} \mathrm{OH}$ in chloroform, however, separated the two compounds. The ultraviolet spectrum of (Ro) showed maxima of 325, 261 and $254 \mathrm{~m} \mu$ (in $\mathrm{CH}_{3} \mathrm{OH}$ ). Its infrared spectrum had an atypical coumarin nucleus as indicated by a loss in absorption at $1,760 \mathrm{~cm}^{-1}$ and, in addition, a broad band at $3,400 \mathrm{~cm}^{-1}$ that suggested a hydroxylated compound. The new isolate was light yellow and decomposed at $230^{\circ}-234^{\circ} \mathrm{C}$ without melting.

Because of the concern about biological and chemical detoxification of aflatoxin in agricultural commodities, this new compound was tested for biological activity. Histopathological examination of bile duct hyperplasia ${ }^{4}$ of the livers from ducklings fed $B_{1}$ for 4 days, followed by death on the sixth day, has been used as a biological assay for the presence of the toxin, for a total dose of $2.5 \mu \mathrm{g}$ can be reproducibly determined. In the conditions specified for the duckling biliary hyperplasia assay ${ }^{4}, 56 \cdot 0 \mu \mathrm{g} \mathrm{B}_{2}$ had the same biological activity as $1.0 \mathrm{mg}$ of the new conversion product, making this product eighteen times less toxic than aflatoxin $B_{1}$ by histopathological assay. Teunisson and Robertson ${ }^{3}$ have reported a modified $\mathbf{B}_{\mathbf{1}}$ aflatoxin produced by Tetrahymena pyriformis with a similar $R_{F}$ value; however, toxicity studies on this compound were not performed.

R. W. Detroy

C. W. Hesseltine

Northern Regional Research Laboratory,

Peoria, Illinois.

Received May 15; revised July 4, 1968.

${ }^{1}$ Holzapfel, C. W., Steyn, P. S., and Purchase, I. F. H., Tetrahedron Lett.; 25, 2799 (1966).

${ }^{2}$ Dulaney, E. L., McAleer, W. J., Barkemeyer, H. R., and Hlavac, C., Appl. Microbiol., 3, 372 (1955).

3 Teunisson, D. J., and Robertson, J. A., Appl. Microbiol., 15, 1099 (1967).

* Wogan, G. N., Mycotoxins in Foodstuffs (edit. by Wogan, G. N.) (MIT Press, 